\title{
Stock movement prediction
}

\author{
V.A.W. Hapsari \& R. Rokhim \\ University of Indonesia, Indonesia
}

\begin{abstract}
Economic growth in the 21st century relies on the participation of the people in economic activities (e.g., trade and commerce and investing). In Indonesia, one particularly common economic activity is to invest in the stock market due to the wide array of companies that investors could choose to invest in. Therefore, this paper will discuss the prediction of stock prices using the Gauss-Newton representation-based algorithm (GNRBA). The proposed method provides users with a more effective algorithm. Investors and potential investors could use the methods discussed in this paper to make an informed decision in investing.
\end{abstract}

\section{INTRODUCTION}

The integration of international economies creates an interdependency between all the countries in the world. As economies across the world integrate more, there will be more transfer of goods, services, and capital. In the context of macroeconomy, capital investment is a component of a country's national income, better known as gross domestic product (GDP), based on the following equation: $\mathrm{Y}=\mathrm{C}+\mathrm{I}+\mathrm{G}+(\mathrm{x}-\mathrm{m})$, where $\mathrm{Y}$ refers to GDP, $\mathrm{C}$ refers to public consumption, I refers to the total investment, $\mathrm{G}$ refers to government spending, $\mathrm{x}$ refers to export, and $\mathrm{m}$ refers to import. GDP is directly in proportion with investment, which means that as investment increases, GDP will also increase. Investment is one of the major drivers of Indonesia's economic growth because the inflow of capital through investments can be used to produce goods and services for the general public. The amount of investment in Indonesia has been growing quite significantly. A report from the United Nations Conference on Trade and Development (UNCTAD) titled "World Investment Report 2019" states that Indonesia is ranked 18th in FDI inflows. The collective FDI inflow of Asian countries grew by $4 \%$ to $\$ 512$ billion. This growth is due to the increase of FDI inflows to China, Hong Kong, Singapore, and Indonesia (United Nations Conference on Trade and Development (UNCTAD), 2019).

The recorded investment in the Indonesian stock market grew year on year. One factor that stimulated this growth is a regulation issued on 6 January 2014 by Otoritas Jasa Keuangan (OJK), which changed the minimum amount for purchasing stocks in the stock market. This new regulation stated that the minimum amount of shares that can be bought is 100 shares, and it allowed more Indonesians to buy shares from the stock market with less capital required. According to Badan Koordinasi Penanaman Modal (BKPM), the amount of investment in the Indonesian Stock Exchange in 2015 to 2019 has been steadily increasing. There is a 30\% growth in investors (1.1 million investors in 2019) based on the Single Investor Identification (SID) compared to previous years (Badan Koordinasi Penanaman Modal (BKPM), 2020).

The stock market has a noisy characteristic, which refers to the lack of holistic information regarding the behavior of the stock market. This lack of information is known as noise. The nonstationary characteristic of the stock market demonstrates the ever-changing distribution of the financial time series. The financial time series is random in the short term but is rather predictable in the longer term (Kumar \& Thenmozhi, 2006). Unpredictable factors and occurrences (e.g., sudden political changes, traders' expectations, and a global pandemic) could alter the financial time series, such as the composite stock index. Additionally, the correlation between the financial 
time series with other data series could also shift in time. Taking all these factors into account, reading the movement of the stock market is challenging.

To minimize risk in the stock market, multiple research studies have been done to predict the movement of the stock market using machine learning to help investors in the stock market, such as support vector regression (Bao, Liu, Guo, \& Wang, 2005), random forest (Kumar \& Thenmozhi, 2006), decision tree (Tiwari, Pandit, \& Richhariya, 2018), and artificial neural networks (Patel, Shah, Thakkar, \& Kotecha, 2015). This research will utilize the Gauss-Newton representationbased algorithm (GNRBA). The writer chose this method of machine learning because there has not been any research studies using the GNRBA method to predict the movement of the stock market. In previous research, the GNRBA method is proven to have an accuracy rate of $98 \%$ when used to study breast cancer (Dora, Agrawal, Panda, \& Abraham, 2017) and cervix cancer (Rustam, Hapsari, \& Solihin, 2019).

\section{LITERATURE REVIEW}

\subsection{Technical analysis indicators}

Various methods can be used to predict the movement of stock prices. One such method is to use technical analysis, which examines patterns in past stock price movements. This historical data is the independent variable (explanatory) in examining technical analysis indicators. These indicators are mathematical formulas, which use stock prices and transaction volumes to find a pattern to the movement of the corresponding stock price (Achelis, 2001). In this research, there will be nine technical indicators used: moving average (MA) comprised of simple moving average (SMA) and exponential moving average (EMA), moving average convergence/divergence (MACD), momentum (MOM), relative strength index (RSI), stochastic oscillator (SO) \% $\mathrm{K}$ and $\% \mathrm{D}$, rate of change (ROC), and commodity channel index (CCI).

\section{METHODOLOGY}

\subsection{Data validation}

The raw data supplied to the algorithm will be separated into two categories: training data, for model creation purposes in machine learning, and data testing, for analyzing the data model and to measure the accuracy of the model. The data is separated by utilizing a data cross-validation method, namely, stratified shuffle split (Pedregosa, 2011).

The data will randomly be categorized randomly into $\mathrm{k}$ group(s). Each data group has a balanced class proportion, which will be randomized with each iteration of the algorithm. This results in the algorithm getting better chances to learn from different data compositions to achieve the highest accuracy rate possible.

\subsection{Gauss-Newton representation-based algorithm}

The Gauss-Newton algorithm started from a data model paired to the actual data, data $\left(S_{i}, t_{i}\right)$, where $i=1,2, \ldots, n$ will be adjusted according to the model $p\left(\beta, s_{i}\right)$ which is nonlinear to $s$, while $t_{i}$ is the result of the actual data. The purpose of utilizing this model is to ensure a fit, which reduces the residue between the data models and the data (Dennis \& Schnabel, 1996).

In this research, $g_{i}(s)=p\left(\beta, s_{i}\right)-t_{i}$ is a function of the smallest nonlinear quadratic problem

$$
\min _{\beta} \sum_{i=1}^{n}\left(p\left(\beta, s_{i}\right)-t_{i}\right)^{2}
$$

where $\beta$ is the parameter, $p(\beta, s)$ is the data-fitted model, $n$ is the amount of data and $\left(s_{i}, t_{i}\right)$, and $s_{i} \in \mathbb{R}^{d}, t_{i} \in \mathbb{R}, n \geq 1, d \geq 1$. 


\section{EXPERIMENTS}

The stock price data used as the input to the GNRBA program is a data set of 1,264 rows of daily stock prices (with adjusted closing) and 17 columns of technical analysis indicators consisting of SMA10, SMA12, SMA20, SMA26, SMA50, EMA10, EMA12, EMA20, EMA26, EMA50, $\% \mathrm{~K}, \% \mathrm{D}, \mathrm{MOM} 9, \mathrm{ROC} 12, \mathrm{MACD}, \mathrm{RSI}$, and CCI; one weekly average price column, one column to indicate whether the stock price is higher or lower compared to the weekly average price column, one holistic average price column, one column to indicate whether the stock price is higher or lower compared to the holistic average price column, and one column to indicate whether the stock price is higher or lower compared to the previous trading day (daily). If the current stock price is higher compared to the previous day's price, then the stock price movement is defined as increasing. Conversely, if the current stock price is lower compared to the previous day's price, then the stock price movement is defined as decreasing. However, if the current stock price is similar to the previous day's price, the author would define this as increasing (considering its stability).

Table 1. A Comparison of the GNRBA Method's Accuracy to the Daily Stock Price of UNVR, MYOR, and ICBP from 2015 to 2019.

\begin{tabular}{lll}
\hline Issuer & Highest Accuracy & Lowest Accuracy \\
\hline UNVR & $95.35 \%$ & $92.76 \%$ \\
MYOR & $90.70 \%$ & $86.90 \%$ \\
ICBP & $93.02 \%$ & $89.51 \%$ \\
Overall & $95.35 \%$ & $86.90 \%$ \\
\hline
\end{tabular}

Table 1 shows the result of the GNRBA method used on UNVR, MYOR, and ICBP, which shows that the highest result accuracy is recorded when using the UNVR stock price as its input, where the data composition used is divided into $30 \%$ data testing and $70 \%$ data training. This composition yielded an accuracy of $95.35 \%$. Meanwhile, the result of the GNRBA method used on UNVR, MYOR, and ICBP shows that the lowest result accuracy is recorded when using the MYOR stock price as its input, where the data composition used is divided into $20 \%$ data testing and $80 \%$ data training, yielding an accuracy of $86.90 \%$.

\section{CONCLUSION}

The computation of the GNRBA is executed by calculating the Euclidean distance between testing samples and class contribution. GNRBA yields an accuracy of higher than $90 \%$. With this, the GNRBA can be an alternative solution to aid investors in predicting stock price movements.

\section{REFERENCES}

Achelis. (2001). Technical Analysis from A to Z (2 ed.). New York: McGraw-Hill.

Bao, Y., Liu, Z., Guo, L., \& Wang, W. (2005). Forecasting Stock Composite Index by Fuzzy Support Vector Machines Regression. Fourth International Conference on Machine Learning and Cybernetics, (pp. 35353540). doi:10.1109/ICMLC.2005.1527554

BKPM. (2020, Januari 29). Realisasi Investasi Indonesia 2019 Naik 48,4\% dalam 5 Tahun. Jakarta, DKI Jakarta, Indonesia: Badan Koordinasi Penanaman Modal. Retrieved Juni 17, 2020, from https://databoks.katadata.co.id/datapublish/2020/01/29/realisasi-investasi-indonesia-2019-naik-484-dalam-5-tahun\#

Dennis, J., \& Schnabel, R. (1996). Numerical Methods for Unconstrained Optimization and Nonlinear Equations. New Jersey: Prentice-Hall. 
Dora, L., Agrawal, S., Panda, R., \& Abraham, A. (2017). Optimal Breast Cancer Classification using Gauss- Newton Representation Based Algorithm. Expert Systems with Applications, 85, 134-145. doi:10.1016/j.eswa.2017.05.035

Kumar, M., \& Thenmozhi, M. (2006). Forecasting Stock Index Movement: A Comparison of Support Vector Machines and Random Forest. 9th Capital Markets Conference Paper. Indian Institute of Capital Markets. doi:10.2139/ssrn. 876544

Patel, J., Shah, S., Thakkar, P., \& Kotecha, K. (2015). Predicting Stock and Stock Price Index Movement using Trend Deterministic Data Preparation and Machine Learning Techniques. Expert System Application, 42(1), 259-268.

Pedregosa, e. a. (2011). Scikit-learn: Machine Learning in Python. Journal of Machine Learning Research, 12, 2825-2830.

Rustam, Z., Hapsari, V., \& Solihin, M. (2019). Optimal Cervical Cancer Classification using Gauss-Newton Representation Based Algorithm. 4th International Symposium on Current Progress in Mathematics and Sciences. 2168(1), pp. 020045-1-020045-6. Jakarta: AIP Conference Proceedings. doi:10.1063/1.5132472

Tiwari, S., Pandit, P., \& Richhariya, P. (2018). Predicting Future Trends in Stock Market by Decision Tree Rough- set Based Hybrid System with HHMM. International Journal of Electronics and Computer Science Engineering, 1(3), 1578-1587. Retrieved from https://pdfs.seman-ticscholar.org/29a7/e1e1386 db50bbb22710d63eb820f9c86ae1b.pdf

UNCTAD. (2019). World Investment Report. Switzerland: United Nations Conference on Trade and Development. Retrieved June 17, 2020, from https://unctad.org/en/PublicationsLibrary/wir2019_overview_en.pdf 